Reseñas

\section{Pierre Penet y Juan Flores Zendejas (eds.). Diplomacies: Rethinking Sovereign Debt from Colonial Empires to Hegemony. Oxford, Oxford University Press, 2021, 352 pp. ISBN: 978-0198866350.}

La deuda soberana y su problemática histórica es un tema fundamental para cualquier país. En momentos de crisis cuando la emisión de deuda es clave para enfrentar la caída de la economía, los tomadores de decisiones evitan hablar del tema. Tanto las economías desarrolladas como aquellas en desarrollo recurren, en mayor o menor medida, a la emisión de deuda para resolver sus problemas más urgentes. No obstante, las últimas son las que se llevan la peor parte, puesto que deben pagar mayores tasas de interés debido a la volatilidad de su propia economía, y por la posibilidad de que las tasas de interés en las economías desarrolladas aumentan también.

El libro plantea una cuestión fundamental: el costo de resolver los problemas presentes no puede comprometer el futuro de las naciones. El objetivo de los autores es invitar al lector a reflexionar sobre la complejidad de la gestión de las negociaciones de deuda soberana; es decir, quiénes y cómo deberían asumir los costos de las deudas incumplidas. Además, deudas heredadas y negociaciones draconianas demuestran que muchas negociaciones incluyen intereses políticos, comerciales, de alianza y agenda que van más allá de lo meramente económico. Los autores plantean el concepto de la diplomacia de deudas soberanas para englobar todos los intereses en las negociaciones de deuda. Esta idea es el resultado de la mezcla entre dos órdenes. Por un lado, las prácticas relacionadas con el repago, y por otro, los modelos normativos que aluden a cláusulas legales, mecanismos de negociación y la concepción de la responsabilidad del Estado.

El cambio de los roles del Estado a lo largo de la historia es un aspecto indispensable para descifrar la propuesta de los autores sobre la diplomacia de deudas soberanas: desde la figura del Estado como una pasiva institución de monitoreo en los conflictos de deuda hasta su presencia como un defensor activo de los derechos de propiedad. La evolución de esta figura ha reconfigurado los intereses de los prestatarios y los prestamistas en las renegociaciones de deuda.

El libro está organizado en cuatro secciones y cada una presenta diversos ejemplos a los que se adapta el enfoque de la diplomacia de deudas, dando paso a una reclasificación. En la primera sección se analizan episodios de impago entre 1820 y 1933 , lo que los autores definen como un enfoque de la diplomacia de deuda imperial. En la segunda, los impagos de deuda transcurridos entre 1933 y 1970 son examinados mediante el enfoque de la diplomacia de deuda inter-Estados. En la tercera, analizan las disputas que surgen en las transiciones poscoloniales desde 1960 a 1980, lo que se considera como la diploma- cia de deuda poscolonial. En la última sección abordan un enfoque de la diplomacia de deudas hegemónicas a partir de 1990.

En la primera sección se presentan ejemplos como los de América Latina, Egipto, Túnez y las excolonias británicas, en los que se aprecia cómo los antecedentes coloniales, en algunos casos, facilitaron el acceso a los mercados de crédito. En otros, condicionó su entrada y, sobre todo, estas relaciones previas a la venta de bonos contribuyeron para que los antiguos imperios siguieran influyendo en las recién independizadas naciones. La deuda y su repago fue considerada un aspecto civilizatorio que produjo la aparición de un entramado legal, institucional y metodológico de evaluación de riesgo. Estos elementos generadores de los mercados de deuda desempeñaron un papel clave para que las negociaciones fueran desiguales a favor de los intereses de las naciones acreedoras. Las injustas negociaciones y la ideología que las acompañó promovieron ciclos de mayor endeudamiento que pocas naciones pudieron sortear. Los resultados demostraron que en algunos casos el acceso al mercado estuvo condicionado por el comportamiento de la economía más que por las relaciones coloniales. Sin embargo, es muy difícil imaginar que alguna de estas naciones no necesitara apoyo para relanzar sus economías.

En la segunda sección, el contexto histórico adquiere mayor relevancia respecto a las disputas de deuda. Esto porque a pesar de que el repago fue retomado de 1933 a 1970, los mercados internacionales de deuda fueron virtualmente cerrados en 1945. La falta de mecanismo para presionar a los deudores de repagar disparó los incentivos para que estos incumplieran sus compromisos. De esta forma, el papel del Estado en las negociaciones de repago fue clave. En países morosos como México y Alemania, la intervención de los Estados de las naciones acreedoras tuvo un interés más allá del que los inversores obtuvieran sus beneficios, y que las economías deudoras cubrieran sus adeudos. Mediante negociaciones ad hoc con los deudores, los Estados promovieron sus propios intereses políticos, geopolíticos y comerciales. Por tanto, algunos acreedores fueron obligados a perdonar importantes montos de deuda a cambio de intereses superiores.

La tercera sección examina cómo las disputas de deuda se insertan en la pugna de los países independizados por establecer un nuevo orden económico internacional con base en la justicia e igualdad entre los Estados. En este caso, tales disputas se analizan a través del problema de las deudas heredades que limitan el acceso al crédito. El acceso limitado del crédito puso en riesgo la consolidación de la soberanía de dichas naciones. En el actual debate académico sobre el análisis de la evolución de la ley internacional, organizaciones y acuerdos internacionales, se resalta el triunfo de las políticas neoliberales que aseguran los derechos de propiedad. Destaca el caso de la Conferencia de las Naciones Unidas sobre Comercio y Desarrollo, cuya participación en los países en desarrollo esta reducido a asesorías técnicas para mejorar la gestión pública y re- 
ducir las probabilidades de impago y sobreendeudamiento. Por lo tanto, desde 1960 los problemas de la deuda son abordados en la esfera de lo local, lo que ha reducido el concepto de soberanía al acceso a los mercados de capital.

En la última sección, con estudios de caso de Argentina, Venezuela y Puerto Rico, los autores presentan los efectos de resolver en cortes locales -como agentes privados- los problemas del pago de la deuda. Concluyen que esta modalidad incrementa la percepción de riesgo e incertidumbre que, a su vez, encarece los costos del repago. El escenario postimpago promueve un mayor ciclo de endeudamiento y disrupción política de los Gobiernos en problemas. La falta de mecanismos generales de disputa en la ley produce los incentivos para que los países acreedores busquen acuerdos ad hoc, por lo que se sugieren cambios en la ley y en las condiciones contractuales para evitar que la disputa de algunos pocos acreedores provoque crisis en otros países. A estas propuestas se añade la mayor coordinación de los organismos internacionales y de la sociedad civil para que los Gobiernos considerados corruptos o ilegítimos encuentren dificultades para acceder a los mercados de deuda.

La crítica principal del libro es que al incluir una gran cantidad de visiones desde diferentes áreas del conocimiento, queda difusa la integración de los objetivos específicos de los capítulos. No obstante, esta amplia visión de enfoques sigue representando uno de los aspectos más interesantes e innovadores del libro. Por tanto, la exposición más directa y coordinada de los conceptos y objetivos de cada capítulo permitiría una más rápida lectura.

En general, el libro introduce un concepto innovador sobre la deuda soberana. Su objetivo es poderoso e invita a profundizar sobre estas cuestiones. La sutileza en el lenguaje empleado y su enfoque plural son unos de los aspectos más destacados.

Marisol L. Romero Universitat de Barcelona

https://doi.org/10.33231/j.ihe.2022.01.012 